Int. J. Electrochem. Sci., 12 (2017) $6908-6919$

\title{
Instantaneous Impedance Analysis of Non-Stationary Corrosion Process: a Case Study of Carbon Steel in $1 \mathrm{M} \mathrm{HCl}$
}

\author{
Jacek Ryl ${ }^{1, *}$, Lukasz Gawel ${ }^{1}$, Mateusz Cieslik ${ }^{1}$, Husnu Gerengi ${ }^{2}$, Grzegorz Lentka ${ }^{3}$, Pawel Slepski $^{1}$ \\ ${ }^{1}$ Department of Electrochemistry, Corrosion and Materials Engineering, Gdansk University of \\ Technology, Narutowicza 11/12, 80-233 Gdansk, Poland \\ ${ }^{2}$ Corrosion Research Laboratory Department of Mechanical Engineering, Duzce University, 81620, \\ Düzce, TURKEY \\ ${ }^{3}$ Department of Metrology and Optoelectronics, Gdansk University of Technology, Narutowicza \\ 11/12, 80-233 Gdansk, Poland \\ *E-mail: jacek.ryl@pg.gda.pl
}

doi: $10.20964 / 2017.07 .15$

Received: 21 March 2017 / Accepted: 2 May 2017 / Published: 12 June 2017

The paper concerns the problem of evaluation of stationarity of carbon steel corrosion in $1 \mathrm{M} \mathrm{HCl}$. Comparison of corrosion rate with addition of corrosion inhibitor to the reference measurement is the most often used way of evaluating inhibitor efficiency. Such an approach is valid only if corrosion rate is a stationary process. Two complementary techniques were used simultaneously: volumetric analysis of evolved hydrogen and instantaneous impedance spectroscopy monitoring. Changes of the electrode surface area and chemical composition have a major impact on the dynamics of both cathodic and anodic processes. On the base obtained results, authors claim that the stationarity of the process determined most often on the base of corrosion potential is ineffective and insufficient.

Keywords: corrosion, carbon steel, impedance monitoring, volumetric analysis

\section{FULL TEXT}

(C) 2017 The Authors. Published by ESG (www.electrochemsci.org). This article is an open access article distributed under the terms and conditions of the Creative Commons Attribution license (http://creativecommons.org/licenses/by/4.0/). 